\title{
Effect of Excluding Travel Time Variations in Urban Areas on Emissions
}

\section{Chaher Alzaman*}

Business and Engineering Management Department, Higher Colleges of Technology, UAE

\begin{abstract}
The literature on Green Supply Chains is growing in importance as production and transportation of goods make a significant contribution to greenhouse emissions worldwide. The literature indicates an increasing number of papers in the field but however also shows a gap for further research. This work looks at transportation through urban areas with high population densities and evaluates the impact of idle transportation time which is due to frequent stops through congested traffic. The work compares fuel consumption costs, and their corresponding $\mathrm{CO}_{2}$ emissions, due to driving time variations to the case when idle time and driving time variations are not considered. This work is a comparison study between the case when driving time variations is not considered and the case when it's included. The overall goal is to show how significant are the $\mathrm{CO}_{2}$ emissions due to driving time variations in a supply chain network of which transportation runs through urban sprawls.
\end{abstract}

Keywords: Supply chain modeling; Supply chain management; Mathematical programming; Green supply chains; $\mathrm{CO}_{2}$ reduction; Sustainability; Transportation models

\section{Introduction}

A common definition for sustainable development is 'development that meets the needs of the present generation, without compromising the ability of future generations to meet their own needs' [1]. On the other hand, a supply chain can be defined as an integrated process of various business entities interacting with each other to source, process and distribute value added products or services to customers [2]. High $\mathrm{CO}_{2}$ emissions can scarify the ability of future generation needs and hence much research has been carried to ways or methods to reduce it. $\mathrm{CO}_{2}$ emissions due to supply chain activities can be considerable. According to Barth and Boriboonsomsin [3] approximately one third of US's carbon dioxide is due to the movement of goods and people.

The paper looks at supply chain models and its consideration of idle transportation due to driving through urban congested areas. This is the case especially in Emerging Countries where cities' infrastructure is really stretched by the movement of material and people. The paper reviews papers that do explicitly model $\mathrm{CO}_{2}$ emission in the overall supply chain model and papers that do not explicitly do so. The motive is to see whether there had been any work that addresses idle transportation time in the literature. The work finds a gap and introduces the question of whether the idle transportation time is significant or not. The green supply chain literature might have not considered idle transportation time because material transportation in global setting crosses thousands of kilometers via sea and hence the component of travel that is through urban areas would not be significant. However, in the case of the Middle East, regional trading is becoming more important. With regional trading, transportation through urban areas becomes more influential on the overall transportation. Take for the example the UAE, where the simulation study would be carried, he total volume of trade between UAE and rest of GCC (i.e. Gulf Cooperation council, a regional trade organization for Gulf countries) countries has increased by $16 \%$ [4]. Hence, the travel component through urban areas becomes more considerable.

The work notes a gap in literature for work that looks at material transportation through congested urban areas and presents an optimization model that is based on experimentations. All experimentation runs are carried in Abu Dhabi, UAE. Choosing Abu Dhabi as a case study is quite important due the rapid growth of the city which challenges the road infrastructure capacity time and time again. Abu Dhabi is a vertically expanded city with most people using private vehicle. This exacerbates traffic congestion. However, Abu Dhabi is quite aggressive in constructing and expanding its roads which makes it a fair case study compared to other world cities which are challenged with growing population and slow road construction pace which might yield higher $\mathrm{CO}_{2}$ emissions. Further, Abu Dhabi infrastructure is rapidly changing with a new highway built to ease the truck traffic by passing the city via Yas and $\mathrm{Al}$ saidiyat islands. Experimental runs are carried in Abu Dhabi. The experimentations log idle and moving time for given routes and then simulates more scenarios using probabilistic statistical distributions.

\section{Literature Review}

Seuring and Muller [5] review the literature in the domain of sustainable supply chain management which encompasses the work of 191 papers. Out of the 191 papers, 21 papers are modeling papers. These papers emphasize on the integration of environmental and social issues discuss in supply chain modeling and/or model supply chain management with emphasis on green practices. Out of the 21 papers only two works perform quantitative analysis such as mathematical programming, mathematical modeling, simulation, and optimization techniques in general and also explicitly models $\mathrm{CO}_{2}$ emissions quantitatively. First, Ferretti et al. [6] look into the aluminum industry and its consequential environmental impact. Their work considers the main pollutants of carbon monoxide, oxides of nitrogen, particulate matter, and Volatile Organic Compounds (VOCs). In the study they found the main two contributors to pollution in the aluminum industry: Transportation and re-melting. The authors utilize mathematical programming to initiate an objective function to minimize the overall supply chain costs considering level of pollution as a constraint. This constraint is manipulated to fetch different solutions. To start,

*Corresponding author: Chaher Alzaman, Business and Engineering Management Department, Higher Colleges of Technology, UAE, E-mail: calzaman@hct.ac.ae

Received January 23, 2013; Accepted May 26, 2013; Published May 31, 2013

Citation: Alzaman C (2013) Effect of Excluding Travel Time Variations in Urban Areas on Emissions. Ind Eng Manage 2: 114. doi: 10.4172/2169-0316.1000114

Copyright: @ 2013 Alzaman C. This is an open-access article distributed under the terms of the Creative Commons Attribution License, which permits unrestricted use, distribution, and reproduction in any medium, provided the original author and source are credited. 
unbounded solution is give without the pollution constraint and then subsequently a decreasing level of pollution is imposed as a constraint. Second, the work of Nagurney and Toyasaki [7] considers applications to electronic commerce and develop a framework for the modeling and analysis of supply chain networks with multiple criteria which includes environmental criterion. The paper establishes optimality conditions and applies an algorithm for the determination of equilibrium prices. One criterion is to maximize profits across manufactures. Another criterion is to minimize emissions. However the paper is geared toward transfer price dynamics. The paper investigates electronic commerce in the form of $\mathrm{B} 2 \mathrm{~B}$ and $\mathrm{B} 2 \mathrm{C}$ transactions. The paper goal is not to analyze operational costs. The paper makes reference that other criteria could be studied such as the minimization of waste generation in production.

Other modeling papers that look at sustainable supply chain management or environmental issues in supply chain exist. The following papers utilize mathematical techniques to model the supply and also explicitly model $\mathrm{CO}_{2}$ emissions. To begin, Bekkering and Broekhuis [8] investigate Dutch biogas production and look at different sustainable criteria of accounting costs and emissions and assess different sustainability criteria (greenhouse, competition with food, bio diversity, and environment). Abdallah et al. [9] introduce a carbon sensitive supply chain network problem with green procurement. They use a mathematical mixed-integer programming model. The model integrates carbon trading cost with the objective of reducing overall emissions. While Ramudhin et al. [10] introduce a supply chain model which is sensitive to the carbon market. The formulation of the model results in a mixed integer programming problem which focuses on transportation, subcontracting, and production activities on the design of a green supply chain. The model considers multi-product system with multiple nodes of suppliers, plants, distribution centers, and retailers. The cost of $\mathrm{CO}_{2}$ (carbon tax) is integrated into the model. Two alternative models (two objective functions) one for operational cost and $\mathrm{CO}_{2}$ emissions and the second for strictly $\mathrm{CO}_{2}$ emissions reduction in production and shipment and carbon tax reductions. The model integrates transportation and shipment costs along with GHGs (Green House Gases) emission costs or credits. Sundarakani et al. [11] present a generic model using Lagrangian and Eulerian transport method and Finite Difference method to model the carbon footprint across the supply chain. The model follows the heat flux caused by a product entering a supply chain node due to various processes where these processes emit carbon and other wastes. The work categorizes the emission into two: one is stationary caused by the processing and manufacturing of material and the holing of material in warehouse, the other is non-stationary which is the emissions from inbound and outbound logistics. Gabbar [12] presents a model for energy supply. He argues that as known to many researchers, power generation is probably the highest contributor to Green House Gases. Gabbar presents a process object Oriented Modeling and presents and LCA framework. The objective of the model is to minimize environmental impact and specifically minimize $\mathrm{CO}_{2}$ emissions. Transportation is not considered in the work. Bojarski et al. [13] address the optimization of the planning and design of the supply chain given environmental and economic considerations. The work carries the modeling the supply chain with attributes of facility location, processing technology selection, and the production distribution planning. A life cycle assessment approach is used to integrate the environmental aspects into the overall model. The work uses a case study of Maleic Anhydride (MA) production. Two models are presented, one with $\mathrm{CO}_{2}$ trading consideration and one without for comparison analysis. In their work, they found that raw material production made most environmental impact while transportation and electricity consumption was the least impact.
It is also important to consider papers that do not integrate environmental or sustainability aspects but models the supply chain. The following body work doesn't address green supply chain issues and specifically does not address $\mathrm{CO}_{2}$ emissions. The works of Raj and Rjendran [14], Pakosy et al. [15], Dondo et al. [16], Dun-Ji et al. [17], Liu et al. [18], Ozen et al. [19], Mahar and Wright [20], and Kadir [21] integrate transportation cost as a lumped cost and does not address situations where transportation is carried through urban areas. Hence idle transportation time, due to traffic stops, is not considered in the above works. The research question of this work applies to driving time variations travel through urban areas. Older works also lumped transportation cost and did not differentiate the component of idle transportation. Arntzen et al. [22] provided a comprehensive model in supply chain modeling where cost elements such as purchasing, manufacturing, pipeline inventory, transportation between different plants or sites, and duty costs where integrated. However their model did not consider idle transportation. Other works in the area of supply chain modeling have been reviewed in previous work [23] and also did not address idle transportation time. This is might be due to the fact that supply chain transportation involves extremely long distance travel (i.e. thousands of kilometers) and hence the urban travel time becomes negligible comparatively to the overall travel time. Raj and Rjendran [14] specifically address fixed-charge transportation where the cost is fixed and hence urban condition variations are neglected. The work of Dondo et al. [16] use distance-based transportation cost. However, in countries where there is a great deal of regional trade, the urban travel time becomes more significant comparatively to the overall travel time. The above literature stresses on global supply chain setting where transportation throughout the globe becomes quite substantial in distance compared to the final destination transportation segment which would be through urban areas. However this could be debated with the new trends of regional trading as in the case explained in the paper.

Overall one can note from the above that transportation within Green Supply Chain (GSC) models is marginalized and not given the attention it deserves. According to the University of California Transportation Center, Barth and Boriboonsomsin [3] wrote that "Roughly a third of America's carbon dioxide $\left(\mathrm{CO}_{2}\right)$ emissions come from moving people or goods, and 80 percent of these emissions are from cars and trucks. To reduce $\mathrm{CO}_{2}$ emissions from the transportation sector, policy makers are primarily pushing for more efficient vehicles, alternative fuels, and reducing Vehicle Miles Traveled (VMT)."

Moreover, the majority of the works focuses on emission resulting from production and processing and does focus on transportation. Moreover, none of the work in the literature review carried in this paper does consider transportation through congested urban areas.

\section{Research Question}

Transportation between supply chain entities cannot be treated generally without paying attention to the terrain on which transportation is taking place. Supply chain transportation for big global companies involves shipping, moving material via railway, and trucking. For regions that lack railway systems, transportation between shipping hubs or distribution to urban areas is carried by vehicles. A portion of the journey is probably via highways which might not be congested resulting in better fuel consumption economics and hence less $\mathrm{CO}_{2}$ emissions than would be the case in urban areas where traffic congestion is more common. In some cities, short trip durations could be exacerbated to longer ones due to traffic congestion. In urban area 
there is a series of street junctions resulting in many idle activities of stopping at traffic lights, stopping at stop signs, and other frequent stops due to bumper-to-bumper traffic. All these idle activities still consume fuel and still emit $\mathrm{CO}_{2}$. Hence, logistics through urban area can yield higher figures in fuel consumption and $\mathrm{CO}_{2}$ emissions. This paper looks at the impact of urbanization on logistical costs and $\mathrm{CO}_{2}$ emissions and specifically the paper looks at the magnitude of it. The research question is of this work is to evaluate the magnitude of $\mathrm{CO}_{2}$ emissions in urban sprawls and corresponding costs for different real life scenarios. The scenarios are set in Abu Dhabi and encompass the case when material handling is taking place in areas at the fringes of the urban concentration of Abu Dhabi, the case when material handling is taking place in areas at the fringes of the urban concentration of $\mathrm{Abu}$ Dhabi at rush hours, the case when material handling is destined to the center of the city, and the case of random material handling that can take place anywhere in the city.

\section{Design of Experiment}

To test the hypothesis, an experiment is conducted to see the time variation of different trips of material transportation through the city of Abu Dhabi as a case study. Abu Dhabi (UAE) is used as a case study as it is a good representation of congested traffic in world urban development. The city has grown in size considerably in the past 10 years like most of other cities in the world. The city lay on a grid traffic system (road infrastructure in Abu Dhabi lays on a straightforward grid system with evenly spaced roads horizontally and vertically; (Figure 1). Trip durations per kilometer are quite similar in the urban concentration of the city due to the grid system where traffic lights are evenly distributed. This is an advantage for the design of experiment as any trip within the urban concentration would be subjected to somewhat similar traffic conditions.

Given the special traffic topography of Abu Dhabi (Figure 1), the paper would take into consideration two population concentrations, one that is at the edges of the urban sprawls (squares) and another at the core of the city (i.e. inner dwelling; ellipses). Each block within the grid harbors approximately 10,000 residents. Hence the first route is chosen for material traveling from distributers to location within the boundaries of urban sprawl. And this route is dissected into two scenarios one for rush hours and another for normal time. The other route cuts deep into the center of urban dwellings. In the simulation runs, it was not noticed that there is a significant difference between rush hours and normal day time hours hence the data collected fitted

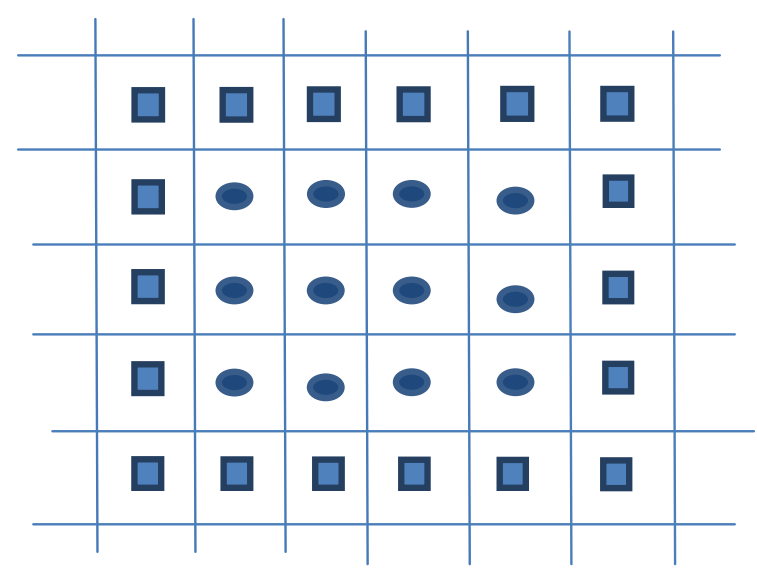

Figure 1: Grid System lay for case study city (Abu Dhabi). a normal distribution without segmenting the data into rush hour and regular hours. On the edges of the city, rush did impact the data sets and hence was segmented into two independent groups of rush hour reading and normal hour readings. All readings are fitted into normal distribution, where the mean and standard deviation are fetched and probabilistic distribution is then simulated for the three different data sets.

To test the significance of the effect of idleness and traffic crowdedness on $\mathrm{CO}_{2}$ emission in urban areas, two experiments, one on a route laying on the edge of the city and another stretching into the inner city dwellings are carried. All routes are within the grid system and hence similar traffic punctuation (traffic lights' frequency) would apply. In the experiments, two elements are measured. The total trip time is measured along with the total stoppage time due to traffic lights and also crowdedness. Idle time is whenever the vehicle is at a complete stop which can be due to traffic lights, stop signs, courtesy to other vehicles, or bumper-to-bumper traffic. More than 100 readings were taken in total. In all readings vehicle type and load on the vehicle are always the same and hence variation is blocked. All courses were driven by the same driver so driving behavior variations are blocked. The duration for each trip is measured in seconds and each individual stop is also logged in seconds. Given the constant load and an average city driving speed of $60 \mathrm{~km} / \mathrm{hr}$ two readings are fetched. The first reading is the duration when the car is in full stop (i.e. idle time) and the second one is when the car is moving at an approximate speed of $60 \mathrm{~km} / \mathrm{hr}$.

The design of experiment entitles carrying an experiment that is representative of congested traffic in urban areas. The routes for the experimentation are picked strategically across the urban concentration of the city. For instance, one of the routes chosen is popular for material movement as it is between the edges of the urban sprawls and areas where distribution centers, plants, and warehouses are. Other routes extend into the center of urban areas where congestion and possibility of delays are high.

\section{Model}

The objective function minimizes the transportation cost and $\mathrm{CO}_{2}$ emissions between distributers and customer groups, with reference needed to equation 4 and 5 .

\section{Sets}

$\mathrm{I}=$ Set of Distributers: all sets of distributers i's.

$\mathrm{J}=$ Set of Customer Groups: all sets of customer groups $j$ 's.

\section{Model parameters}

$\mathrm{COT}_{\mathrm{i}, \mathrm{p}, \mathrm{p}}=\mathrm{CO}_{2}$ emissions due to transportation from distributer i to customer group $\mathrm{j}$ for product $\mathrm{p}$.

$\Phi_{T C i, j, p}=$ Cost Time function which outputs values of transportation cost between distributer $i$ and customer group $j$ for product $p$ in seconds which is a function of idle and moving time (see equations $4 a$ and $5 a$ ).

$\Phi_{\mathrm{CO} i, j, p}=\mathrm{CO}_{2}$ function which outputs values of transportation emissions due to the transportation of product $p$ between distributer $i$ and customer group $j$ in seconds which is a function of idle and moving time

$\mathrm{TC}_{\mathrm{i}, \mathrm{j}, \mathrm{p}}=$ Transportation cost form distributer i to customer group $\mathrm{j}$ for product $p$ (see equation $4 \mathrm{~b}$ ); not function of idle or moving time (exclusion case).

$\mathrm{COT}_{\mathrm{i}, \mathrm{j}, \mathrm{p}}=$ Total emission due to the travel between distributer $i$ to 
customer group $j$ for product $p$ (see equation $5 b$ ); not function of idle or moving time (exclusion case).

$\mathrm{W}_{\mathrm{p}}=$ The total load (kilograms) of product $p$ that are transported in one load of transport

$\mathrm{CAP}_{\mathrm{I}, \mathrm{p}}=$ Capacity of distributer $i$ for product $p$;

$\mathrm{DEM}_{\mathrm{j}, \mathrm{p}}=$ Demand of product $p$ at customer group $j$;

\section{Decision variables}

$\mathrm{XT}_{\mathrm{i}, \mathrm{j}, \mathrm{p}}=$ Total products $p$ transported from distributor $i$ to customer group $j$;

$\mathrm{XT}_{\mathrm{j}, \mathrm{p}}=$ Total products arriving from distributors to each customer group $j$ for product $p$.

Minimize (transportation):

$$
\begin{aligned}
& \sum_{i \in I} \sum_{j \in J} \sum_{p \in P} \Phi_{T C_{i, j, p}} X T_{i, j, p} \frac{1}{W_{p}}+\sum_{i \in I} \sum_{j \in J} \sum_{p \in P} \Phi_{C O_{i, j, p}} X T_{i, j, p} \frac{1}{W_{p}} \\
& \text { Or } \\
& \sum_{i \in I} \sum_{j \in J} \sum_{p \in P} \mathrm{TC}_{\mathrm{i}, \mathrm{j}, \mathrm{p}} X T_{i, j, p} \frac{1}{W_{p}}+\sum_{i \in I} \sum_{j \in J} \sum_{p \in P} C O T_{i, j, p} X T_{i, j, p} \frac{1}{W_{p}}
\end{aligned}
$$

Constraint 2 ensures that the demand at the customer groups for product $\mathrm{p}$. Constraint 3 ensures that the distributer has enough capacity to meet the demand.

\section{Subject to,}

\section{Demand constraint}

$$
\sum_{i \in I} X T_{i, j, p}=\operatorname{Dem}_{j, p} \quad \forall j, \forall p
$$

Capacity Constraint

Procedural Steps

- Take real time readings (idle time and moving time) for two destinations: one to the city edges and another into the inner dwellings of the city.

- Fit the reading data into proper statistical distribution

- Fetch a mean and a standard deviation for the readings

- Generate random instance using normal distribution for the given standard deviation and mean using MATLAB

Figure 2: Procedure for experiment and simulation steps

$$
\sum_{j \in J} X T_{i, j, p} \leq \operatorname{Cap}_{i, p} \quad \forall i, \forall p
$$

\section{Simulation}

After taking all the readings discussed in the design of experiment, the data is statistically analyzed. Runs in the design of experiments record distance traveled to nearest 0.1 of a kilometer, idle times, and total traveled time. An example of these recordings is depicted in Table 1. This is the first step in the methodology shown in Figure 2 where data is recorded as prescribed in the experimentation section. The next step is to fit the reading data into the respective statistical distribution given its mean and standard deviation. In more detail, the readings from Table 1 are plotted in a histogram which illustrated normal distribution. Here, the standard deviation and mean are computed and based on that a unique normal distribution is constructed with a unique standard deviation and mean. The said unique distribution is used to generate random numbers and hence simulation. The work utilizes a built-in-function within MATLAB (very common mathematical and educational software) to generate random numbers based on the given standard deviation and mean. This allows for performing of hundreds of simulation runs for any given experimental readings to better assess the magnitude of $\mathrm{CO}_{2}$ emission and transportation costs.

In the simulated random inputs, which are based on normal distribution that fitted the original data, all duration lengths are standardized to one kilometer. Below is a sample of readings.

Since, the aim of the paper is to compare between two different cases one where idle and driving variation due to congestion are accounted for (inclusion case) and second where the these considerations are not integrated and the traveling routes are assumed to be based on distance traveled rather than time traveled (exclusion case): it is important to discuss the two cases.

The first case is an exclusion case which utilizes the objective function (1b) in the mathematical model discussed. The exclusion case only considers the distance between distributers and customer groups and does not take into account variation due to traffic congestion. Hence, the cost and emission of transportation from point $A$ to point $B$ is only function of distance and not time or other factors.

The inclusion case, which utilizes the objective function (1a) in the mathematical model discussed, takes into account urban traffic

\begin{tabular}{|c|c|c|c|c|c|c|c|c|}
\hline $\begin{array}{l}\text { Kilometers } \\
\text { traveled }\end{array}$ & $\begin{array}{l}\text { Trip Total Duration } \\
\text { (seconds) }\end{array}$ & $\begin{array}{c}\text { First full stop duration } \\
\text { (seconds) }\end{array}$ & $\begin{array}{c}\text { Second full stop duration } \\
\text { (seconds) }\end{array}$ & $\begin{array}{c}\text { Third full stop duration } \\
\text { (seconds) }\end{array}$ & $\begin{array}{c}\text { Fourth full stop duration } \\
\text { (seconds) }\end{array}$ & $\begin{array}{c}\text { Total Stoppage } \\
\text { (seconds) }\end{array}$ & $\begin{array}{l}\text { Total Moving time } \\
\text { (seconds) }\end{array}$ & $\begin{array}{l}\text { Percent of } \\
\text { idle time }\end{array}$ \\
\hline 6.2 & 892 & 57 & 50 & 79 & 90 & 276 & 616 & 30.94 \\
\hline 6.2 & 747 & 90 & 6 & 27 & & 123 & 624 & 16.47 \\
\hline 6.2 & 795 & 96 & 92 & & & 188 & 607 & 23.65 \\
\hline 6.2 & 862 & 96 & 56 & 43 & & 195 & 667 & 22.62 \\
\hline 6.2 & 785 & 96 & 24 & & & 120 & 665 & 15.29 \\
\hline 6.2 & 861 & 96 & 10 & 95 & & 201 & 660 & 23.34 \\
\hline 6.2 & 787 & 96 & 14 & 114 & & 224 & 563 & 28.46 \\
\hline 6.2 & 857 & 52 & 30 & 91 & 88 & 261 & 596 & 30.46 \\
\hline 6.2 & 614 & 13 & 25 & & & 38 & 576 & 6.19 \\
\hline 6.2 & 809 & 42 & 91 & 5 & & 138 & 671 & 17.06 \\
\hline
\end{tabular}
conditions' sensitivities. Because a fixed distance trip does not necessarily translate into straightforward fuel consumption approximation, there may be frequent stopping that involve fuel burning while vehicle is idle. For this case, stoppage time is measured and is integrated into the fuel

Table 1: Instances of experimentation readings. 
consumption calculations; emissions values from the inclusion case are a function of idle time and moving time.

\section{Simulation Runs}

The methodology starts with initiating the input data. The input data is pulled from the normal distribution for each of the data sets (see Figure 2). The value of gasoline consumption and $\mathrm{CO}_{2}$ emissions during idle and moving time were fetched from the Australian fuel consumption Guide [24] and cross referenced to data from Natural Resources Canada Office of Energy Efficiency [25] for a 6 liter engine vehicle (same type of vehicle used for the experimentations). The data procured is specific to the vehicle used for the runs and is as follows,

\section{For inclusion case:}

$\mathrm{CM}=$ Liters of gasoline consumed per minute of driving at $60 \mathrm{~km} /$ $\mathrm{hr}=0.139 \mathrm{~L} / \mathrm{min}$

$\mathrm{CI}=$ Liters of gasoline consumed per minute while car is in full stop (i.e. idle) $=0.042 \mathrm{~L} / \mathrm{min}$

\section{$\mathrm{P}=$ Price of one liter of gasoline $=1 \$ / \mathrm{L}$}

$\mathrm{Em}=$ Kilograms of $\mathrm{CO}_{2}$ emitted for every liter of gasoline consumed= $2.3 \mathrm{~kg} / \mathrm{L}$

$\mathrm{TI}=$ Total time elapsing while vehicle is idle in minutes

$\mathrm{TM}=$ Total time elapsing while vehicle is moving in minutes

Then

$\mathrm{TCI}_{\mathrm{i}, \mathrm{j}, \mathrm{p}}=$ Transportation cost at idle intervals $=\mathrm{CI}_{\mathrm{p}} \mathrm{TI}_{\mathrm{i}, \mathrm{j}, \mathrm{p}}$

$\mathrm{TCM}_{\mathrm{i}, \mathrm{j}, \mathrm{p}}=$ Transportation cost at moving intervals $=\mathrm{CM}_{\mathrm{p}} \mathrm{TM}_{\mathrm{i}, \mathrm{j}} \mathrm{Em}$

$\mathrm{CoI}_{\mathrm{i}, \mathrm{j}, \mathrm{p}}=$ Amount of $\mathrm{CO}_{2}$ emitted in kilograms for every minute of idle time $=\mathrm{CI}_{\mathrm{p}} \mathrm{TI}_{\mathrm{i}, \mathrm{j}} \mathrm{Em}$

$\mathrm{CoM}_{\mathrm{i}, \mathrm{j}, \mathrm{p}}=$ Amount of $\mathrm{CO}_{2}$ emitted in kilograms for every minute of moving time $=\mathrm{CM}_{\mathrm{p}} \mathrm{TM}_{\mathrm{i}, \mathrm{j}} \mathrm{Em}$

$$
\begin{aligned}
& \Phi_{T C i, j, p}=T C I_{i, j, p}+T C M_{i, j, p} ; \forall i, \forall j, \forall p \\
& \Phi_{C O i, j, p}=C O I_{i, j, p}+C O M_{i, j, p} ; \forall i, \forall j, \forall p
\end{aligned}
$$

For the inclusion case, TI and TM which is time duration between distributers and customer groups, is simulated based on the normal distribution which in turn is based on actual experiment readings as discussed in design of experiment.

\section{For exclusion case:}

$E m=$ Kilograms of $\mathrm{CO}_{2}$ emitted for every liter of gasoline consumed= $2.3 \mathrm{~kg} / \mathrm{L}$.

$\mathrm{C}=$ Liters consumed per kilometer traveled $=0.139 \mathrm{~L} / \mathrm{km}$.

$\mathrm{P}=$ Price of one liter of gasoline $=1 \$ / \mathrm{L}$.

D $\mathrm{i}_{\mathrm{j}}=$ Distance traveled between distributer $i$ and customer group $j$ in kilometers.

Then,

$\mathrm{TC}_{\mathrm{i}, \mathrm{j}, \mathrm{p}}=\mathrm{D}_{\mathrm{i}, \mathrm{j}} \mathrm{C}_{\mathrm{p}} \mathrm{P}=$ Transportation cost form distributer i to customer group $\mathrm{j}$ for product $p(4 \mathrm{~b})$.

$\operatorname{COT}{ }_{i, j, p}=D_{i, j} C_{p} E m=$ Total emission due to the travel between distributer $i$ to customer group $j$ for product $p(5 \mathrm{~b})$.

More specifically, random simulation data populates the model discussed in equation 1 and constraints 2 and 3, where the demand and capacities are inputted for each scenario. These input parameters discussed in the model such as Dem ${ }_{\mathrm{j}, \mathrm{p}}$, Cap $\mathrm{i}_{\mathrm{p}, \mathrm{p}}$ and $\mathrm{W}_{\mathrm{p}}$ are not critical since the objective of this paper is two compare between two models, one with inclusion of idle driving time and the other with the exclusion of that. Since, the same input value are used for both models it would not affect the comparative results. Also actual value of the parameters concerning loads on vehicle, type of product transported, and emission per distance traveled can be neglected. In mathematical terms, the parameter which the paper considers for analysis is the percent difference (column 5 in the remaining scenario tables) between the inclusion and exclusion which can be written as follows:

$$
\text { Percent_Difference }=\frac{\mathrm{CO}_{\text {inc }}-\mathrm{CO}_{\text {exc }}}{\mathrm{CO}_{\text {exc }}} \times 100 .
$$

where $\mathrm{CO}_{\text {exc }}$ is the total $\mathrm{CO}_{2}$ emissions in the exclusion case and $\mathrm{CO}_{\text {inc }}$ is the total $\mathrm{CO}_{2}$ emission in the inclusion case. From equation 1,2 , and 3 , we can write $\mathrm{CO}_{\text {exc }}$ and $\mathrm{CO}_{\text {inc }}$ as follows:

$$
\begin{aligned}
& \sum_{i \in I} \sum_{j \in J} \sum_{p \in P} C O T_{i, j, p} X T_{i, j, p} \frac{1}{W_{p}} \\
& \sum_{i \in I} \sum_{j \in J} \sum_{p \in P} \Phi_{C O_{i, j, p}} X T_{i, j, p} \frac{1}{W_{p}}
\end{aligned}
$$

Hence,

$$
\text { perc_Diff }=\frac{\sum_{i \in I} \sum_{j \in J} \sum_{p \in P} \phi_{C O_{i, j, p}} X T_{i, j, p} \frac{1}{W_{p}}-\sum_{i \in I} \sum_{j \in J} \sum_{p \in P} C O T_{i, j, p} X T_{i, j, p} \frac{1}{W_{p}}}{\sum_{i \in I} \sum_{j \in J} \sum C O T_{i, j, p} X T_{i, j, p} \frac{1}{W_{p}}} \times 100
$$

$\mathrm{W}_{\mathrm{p}}$ is a constant and hence could be factored out of the equation. $\operatorname{Dem}_{\mathrm{j} . \mathrm{p}}$ and $\mathrm{Cap}_{\mathrm{i}, \mathrm{p}}$ parameters are in the constraints 2 and 3 and are fixed for both inclusion and exclusion case. Overall, the goal of experiment is to log time for route durations to later fetch fuel consumption and $\mathrm{CO}_{2}$ emissions for the inclusion casual with respect to equations $1 \mathrm{a}$, 2, 3, 4a, and 5a. The simulation runs take the readings and fit them into statistical distribution and then generate numbers to represent a variant number of runs. Then the results are contrasted to the exclusion case where emissions and transportation cost values are computed using equation $1 \mathrm{~b}, 2,3,4 \mathrm{~b}$, and $5 \mathrm{~b}$. Optimization would be used for the two cases to assure that the lowest $\mathrm{CO}_{2}$ emission routes are chosen.

\section{Scenarios}

To better analyze and make results more representative for real life situations, four different scenarios are set. In all the scenarios, two cases are compared; one which is inclusion that takes into account the frequent stopping during the trip and another model that is exclusion and ignores stoppage. The motive is to show the magnitude of idleness in city traveling and to illustrate the resulting carbon emission increases due to these phenomena. The capacity of plants is set fixed for all scenarios. The demand in each scenario might change due to the population count for each scenario. Results of each scenario would be depicted in tabular forms with five columns representing total kilometers traveled (column one), total idle time (column two), total moving time (column three), percent of idle time in relation to total travel time (column four), and the percent difference between the exclusion and inclusion cases in terms of $\mathrm{CO}_{2}$ emissions or transportation cost (column five).

\section{Scenario 1 (edges of city)}

The first scenario focuses on frequent deliveries made between 
distribution centers outside the city to customer concentration that are at the peripheries of the city which harbors an approximate number of 180,000 residents. Hence, deliveries to customer concentration areas deep into the inner-dwelling of the city are omitted from this scenario. Keep in mind that these customer concentrations still involve driving though heavy traffic concentration, however they are milder than the latter scenarios (especially scenario 3 that looks into deliveries to innerdwelling).

Results of 20 simulated runs are illustrated in Table 2. It is important to note that many more 20 group data sets were run. As shown in column 5 , there is $43 \%$ increase in $\mathrm{CO}_{2}$ emissions due to urban congestion. Adequate to notice, the standard deviation of column 5 readings is 2.58. Hence, the difference is significant as it is greater than $40 \%$, which implies that any supply chain model that does not take into account the driving time variation, would underestimate $\mathrm{CO}_{2}$ emissions by almost $43 \%$. Remembering that this model simulates traffic situation at the fringes of congested areas, the numbers would become higher in inner areas as we would see in scenario 3 and 4 . Column four illustrate that the average percentage of idle time compare to total trip time is around $20 \%$. This would be lower than the scenario on the inner city due to the nature of roads that surround the city edges which are semi highways with traffic conjunctions.

\section{Scenario 2 (edges of city with extreme peak hours)}

This scenario is similar to scenario one with the exception that they are carried during rush hours (i.e. early morning and late afternoon). The results presented in Table 3 illustrate that the percent difference (column 5) stands at $53 \%$ which is almost ten points higher than in scenario 1 . The standard deviation of column 5 remains quite similar to scenario 1 at 2.6. This scenario still considers the fringes of the city where idle time is less severe than it is in the inner part of the city.

\section{Scenario 3 (Inner city)}

Scenario 3 considers frequent deliveries between distribution centers outside the city to customer concentration in the inner city areas (ellipses, see Figure 1) which harbors an approximate number of 120,000 residents. The percent difference now becomes $64 \%$ as shown in the average of all column five readings in Table 4. This implies that a supply chain model that does not address driving time variations can underestimate $\mathrm{CO}_{2}$ emissions by $64 \%$ and can also underestimate fuel cost by $64 \%$ where transportation is via urban concentrations. Cautiously, this value is quite high is during rush hour in highly congested areas where highways are at least 5 traffic junctions away. Nevertheless, this is a reality but not representative to overall transportation in urban areas. Observing Table 4, the range becomes higher than Scenario 1 and 2 and the standard deviation of column five's readings is 6.36 which is more than twice higher than Scenario 1 and 2. Hence models that do not consider driving time variations can yield even more extreme values and higher underestimations of emissions because of these high variations. Column four illustrate that the average percentage of idle time compare to total trip time is around $36 \%$ which is around 16 percent points higher than the city edges. According to column 2 in Table 4, stoppage happens more often than previous scenarios due to more frequent stops that are due in part to congestion at traffic junctions.

\section{Scenario 4 (Mixed scenario)}

Scenario 4 simulates a probabilistic model with possibility of deliveries between distribution centers and peripheral areas, between distribution centers and inner city areas, and between distribution centers and peripheral areas and then to inner city areas, and takes into account peak hours and none peak hours. This scenario is more tuned to real life situations where material is transported to inner

\begin{tabular}{|c|c|c|c|c|c|}
\hline \multicolumn{6}{|c|}{ Scenario 1: traffic through city edges } \\
\hline Simulation run & $\begin{array}{c}\text { Column (1) Total } \\
\text { Kilometers traveled (km) }\end{array}$ & $\begin{array}{l}\text { Column (2) Total Idle } \\
\text { Time (minutes) }\end{array}$ & $\begin{array}{c}\text { Column (3) Total Moving } \\
\text { Time (minutes) }\end{array}$ & $\begin{array}{c}\text { Column (4) Percent Idle } \\
\text { Time }\end{array}$ & $\begin{array}{c}\text { Column (5) Percent difference } \\
\text { between the two models (CO2 } \\
\text { emission and cost) }\end{array}$ \\
\hline Run 1 & 1512 & 619.14 & 2307.98 & 21.15 & 46.05 \\
\hline Run 2 & 1512 & 584.17 & 2306.36 & 20.21 & 45.18 \\
\hline Run 3 & 1512 & 605.56 & 2309.47 & 20.77 & 44.65 \\
\hline Run 4 & 1512 & 604.11 & 2320.40 & 20.66 & 48.13 \\
\hline Run 5 & 1512 & 601.00 & 2309.79 & 20.65 & 44.90 \\
\hline Run 6 & 1512 & 604.37 & 2319.08 & 20.67 & 45.86 \\
\hline Run 7 & 1512 & 601.56 & 2317.26 & 20.61 & 45.69 \\
\hline Run 8 & 1512 & 601.54 & 2319.88 & 20.59 & 44.61 \\
\hline Run 9 & 1512 & 608.34 & 2304.91 & 20.88 & 42.66 \\
\hline Run 10 & 1512 & 606.70 & 2301.72 & 20.86 & 44.82 \\
\hline Run 11 & 1512 & 578.66 & 2310.05 & 20.03 & 39.38 \\
\hline Run 12 & 1512 & 625.43 & 2300.92 & 21.37 & 44.35 \\
\hline Run 13 & 1512 & 611.03 & 2298.59 & 21.00 & 42.00 \\
\hline Run 14 & 1512 & 556.64 & 2300.33 & 19.48 & 43.06 \\
\hline Run 15 & 1512 & 619.16 & 2292.37 & 21.27 & 42.15 \\
\hline Run 16 & 1512 & 599.03 & 2299.92 & 20.66 & 41.65 \\
\hline Run 17 & 1512 & 626.30 & 2288.88 & 21.48 & 39.15 \\
\hline Run 18 & 1512 & 596.52 & 2301.75 & 20.58 & 42.28 \\
\hline Run 19 & 1512 & 583.85 & 2306.75 & 20.20 & 41.49 \\
\hline Run 20 & 1512 & 589.90 & 2287.41 & 20.50 & 38.08 \\
\hline Average & 1512.08 & 601.15 & 2305.19 & 20.68 & 43.31 \\
\hline Range & 0.01 & 69.66 & 32.99 & 2.00 & 10.05 \\
\hline
\end{tabular}

Table 2: Results from Scenario 1. 
Citation: Alzaman C (2013) Effect of Excluding Travel Time Variations in Urban Areas on Emissions. Ind Eng Manage 2: 114. doi: 10.4172/21690316.1000114

Page 7 of 9

\begin{tabular}{|c|c|c|c|c|c|}
\hline \multicolumn{6}{|c|}{ Scenario 2: traffic through city edges during rush hours } \\
\hline Simulation run & $\begin{array}{l}\text { Column (1) Total } \\
\text { Kilometers traveled }(\mathrm{km})\end{array}$ & $\begin{array}{l}\text { Column (2) Total Idle } \\
\text { Time (minutes) }\end{array}$ & $\begin{array}{l}\text { Column (3) Total Moving } \\
\text { Time (minutes) }\end{array}$ & \begin{tabular}{|c|} 
Column (4) \\
Percent Idle Time
\end{tabular} & $\begin{array}{l}\text { Column (5) Percent difference between the } \\
\text { two models (CO2 emission and cost) }\end{array}$ \\
\hline Run 1 & 1512 & 764.92 & 2746.06 & 21.79 & 51.59 \\
\hline Run 2 & 1512 & 769.46 & 2762.64 & 21.78 & 56.72 \\
\hline Run 3 & 1512 & 716.16 & 2691.66 & 21.02 & 48.90 \\
\hline Run 4 & 1512 & 723.55 & 2770.46 & 20.71 & 54.29 \\
\hline Run 5 & 1512 & 756.85 & 2685.18 & 21.99 & 51.96 \\
\hline Run 6 & 1512 & 755.46 & 2745.32 & 21.58 & 53.10 \\
\hline Run 7 & 1512 & 771.84 & 2738.13 & 21.99 & 54.71 \\
\hline Run 8 & 1512 & 780.48 & 2709.94 & 22.36 & 54.18 \\
\hline Run 9 & 1512 & 708.31 & 2720.76 & 20.66 & 51.46 \\
\hline Run 10 & 1512 & 742.89 & 2746.69 & 21.29 & 55.98 \\
\hline Run 11 & 1512 & 749.13 & 2659.40 & 21.98 & 49.98 \\
\hline Run 12 & 1512 & 746.12 & 2774.03 & 21.20 & 55.73 \\
\hline Run 13 & 1512 & 742.56 & 2754.81 & 21.23 & 51.32 \\
\hline Run 14 & 1512 & 762.89 & 2797.65 & 21.43 & 57.76 \\
\hline Run 15 & 1512 & 774.38 & 2751.88 & 21.96 & 51.78 \\
\hline Run 16 & 1512 & 754.54 & 2786.00 & 21.31 & 53.89 \\
\hline Run 17 & 1512 & 760.61 & 2716.35 & 21.88 & 53.77 \\
\hline Run 18 & 1512 & 738.38 & 2732.01 & 21.28 & 47.51 \\
\hline Run 19 & 1512 & 754.42 & 2710.48 & 21.77 & 54.56 \\
\hline Run 20 & 1512 & 758.00 & 2731.88 & 21.72 & 52.46 \\
\hline Average & 1512.08 & 751.55 & 2736.57 & 21.55 & 53.08 \\
\hline Range & 0.01 & 72.16 & 138.25 & 1.70 & 10.25 \\
\hline
\end{tabular}

Table 3: Results from Scenario 2

Scenario 3: transportation in city inner dwellings

\begin{tabular}{|c|c|c|c|c|c|}
\hline Simulation run & $\begin{array}{l}\text { Column (1) Total } \\
\text { Kilometers traveled } \\
(\mathbf{k m})\end{array}$ & $\begin{array}{l}\text { Column (2) Total Idle } \\
\text { Time (minutes) }\end{array}$ & $\begin{array}{c}\text { Column (3) Total } \\
\text { Moving Time (minutes) }\end{array}$ & $\begin{array}{l}\text { Column (4) } \\
\text { Percent Idle Time }\end{array}$ & $\begin{array}{l}\text { Column (5) Percent difference between the two } \\
\text { models ( } \mathrm{CO} 2 \text { emission and cost) }\end{array}$ \\
\hline Run 1 & 1008 & 1106.43 & 2066.62 & 34.87 & 70.75 \\
\hline Run 2 & 1008 & 1149.31 & 2026.24 & 36.19 & 67.95 \\
\hline Run 3 & 1008 & 1127.22 & 1976.31 & 36.32 & 62.33 \\
\hline Run 4 & 1008 & 1139.98 & 2010.51 & 36.18 & 61.40 \\
\hline Run 5 & 1008 & 1158.70 & 1997.20 & 36.72 & 62.53 \\
\hline Run 6 & 1008 & 1122.18 & 2033.98 & 35.56 & 69.82 \\
\hline Run 7 & 1008 & 1132.38 & 2025.24 & 35.86 & 60.14 \\
\hline Run 8 & 1008 & 1173.79 & 2008.52 & 36.88 & 58.11 \\
\hline Run 9 & 1008 & 1136.43 & 1993.59 & 36.31 & 72.66 \\
\hline Run 10 & 1008 & 1147.14 & 2003.34 & 36.41 & 65.39 \\
\hline Run 11 & 1008 & 1148.54 & 1984.43 & 36.66 & 54.91 \\
\hline Run 12 & 1008 & 1172.98 & 2067.22 & 36.20 & 80.85 \\
\hline Run 13 & 1008 & 1143.24 & 1995.78 & 36.42 & 56.64 \\
\hline Run 14 & 1008 & 1129.85 & 2031.28 & 35.74 & 64.53 \\
\hline Run 15 & 1008 & 1142.29 & 1999.69 & 36.36 & 62.30 \\
\hline Run 16 & 1008 & 1150.80 & 2022.64 & 36.26 & 72.56 \\
\hline Run 17 & 1008 & 1188.28 & 1989.57 & 37.39 & 60.43 \\
\hline Run 18 & 1008 & 1182.45 & 1969.30 & 37.52 & 64.26 \\
\hline Run 19 & 1008 & 1138.28 & 1940.68 & 36.97 & 60.51 \\
\hline Run 20 & 1008 & 1128.45 & 1952.92 & 36.62 & 69.48 \\
\hline Average & 1008.05 & 1145.94 & 2004.75 & 36.37 & 64.88 \\
\hline Range & 0.01 & 81.85 & 126.54 & 2.65 & 25.94 \\
\hline
\end{tabular}

Table 4: Results from Scenario 3.

parts of the city and also to the fringes of the city. Due to the special features of this scenario where inner and outer parts of the city both are considered the results become milder than scenario 3 where only inner parts are considered. Column 5 in Table 5 shows an overall average of
$49 \%$ while the variation in percent difference becomes higher due to higher variation in outcomes (i.e. rush hour, trips to edges of city, trips to inner city). The standard deviation, for column 5's readings becomes 1.5 , which is lower than it was for scenario 3 . Scenario 3 explicitly only 
Citation: Alzaman C (2013) Effect of Excluding Travel Time Variations in Urban Areas on Emissions. Ind Eng Manage 2: 114. doi: 10.4172/21690316.1000114

Page 8 of 9

\begin{tabular}{|c|c|c|c|c|c|}
\hline \multicolumn{6}{|c|}{ Scenario 4: Mix of three scenarios } \\
\hline Simulation run & $\begin{array}{l}\text { Column (1) Total } \\
\text { Kilometers traveled } \\
(\mathbf{k m})\end{array}$ & $\begin{array}{l}\text { Column (2) Total Idle } \\
\text { Time (minutes) }\end{array}$ & $\begin{array}{l}\text { Column (3) Total } \\
\text { Moving Time } \\
\text { (minutes) }\end{array}$ & $\begin{array}{c}\text { Column (4) } \\
\text { Percent Idle Time }\end{array}$ & $\begin{array}{c}\text { Column (5) Percent difference between the two } \\
\text { models ( } \mathrm{CO} 2 \text { emission and cost) }\end{array}$ \\
\hline Run 1 & 2520 & 1867.49 & 4452.00 & 29.55 & 49.74 \\
\hline Run 2 & 2520 & 1987.08 & 4493.50 & 30.66 & 49.43 \\
\hline Run 3 & 2520 & 1937.26 & 4424.63 & 30.45 & 46.30 \\
\hline Run 4 & 2520 & 1893.06 & 4426.48 & 29.96 & 47.20 \\
\hline Run 5 & 2520 & 1977.82 & 4514.28 & 30.47 & 47.64 \\
\hline Run 6 & 2520 & 1993.95 & 4482.14 & 30.79 & 48.56 \\
\hline Run 7 & 2520 & 2033.04 & 4482.68 & 31.20 & 48.94 \\
\hline Run 8 & 2520 & 1916.81 & 4409.39 & 30.30 & 49.04 \\
\hline Run 9 & 2520 & 1871.21 & 4423.83 & 29.73 & 48.43 \\
\hline Run 10 & 2520 & 2011.60 & 4513.88 & 30.83 & 51.08 \\
\hline Run 11 & 2520 & 2026.60 & 4527.81 & 30.92 & 50.66 \\
\hline Run 12 & 2520 & 1951.05 & 4525.30 & 30.13 & 51.42 \\
\hline Run 13 & 2520 & 1865.89 & 4405.48 & 29.75 & 48.92 \\
\hline Run 14 & 2520 & 1905.02 & 4483.82 & 29.82 & 49.21 \\
\hline Run 15 & 2520 & 1874.73 & 4425.67 & 29.76 & 47.72 \\
\hline Run 16 & 2520 & 1845.21 & 4432.75 & 29.39 & 48.74 \\
\hline Run 17 & 2520 & 2022.05 & 4418.05 & 31.40 & 49.19 \\
\hline Run 18 & 2520 & 1898.61 & 4504.33 & 29.65 & 51.53 \\
\hline Run 19 & 2520 & 1945.51 & 4538.93 & 30.00 & 48.97 \\
\hline Run 20 & 2520 & 1986.67 & 4417.45 & 31.02 & 46.39 \\
\hline Average & 2520 & 1940.53 & 4465.12 & 30.29 & 48.95 \\
\hline Range & 0.01 & 187.84 & 133.45 & 2.01 & 5.23 \\
\hline
\end{tabular}

Table 5: Results from Scenario 4

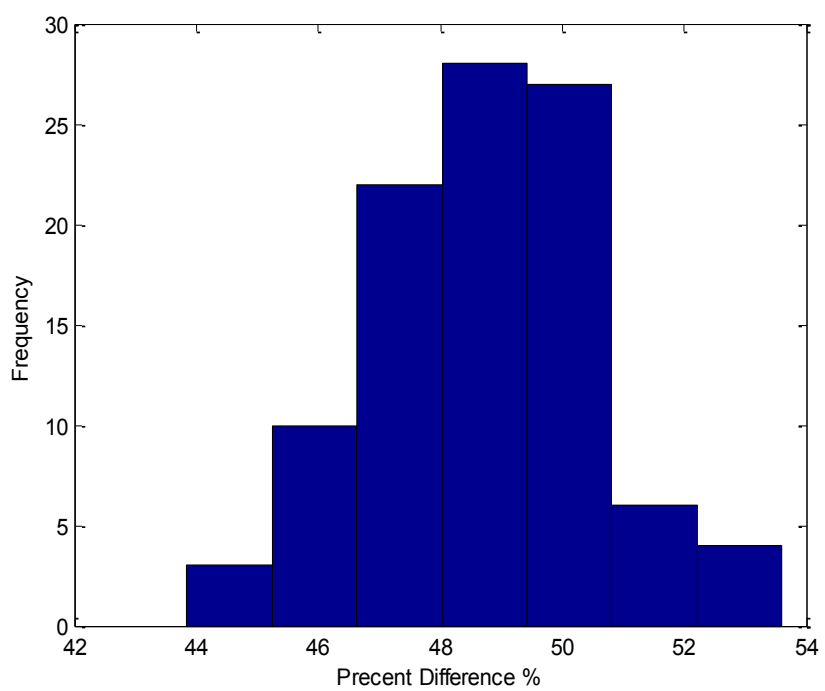

Figure 3: This figure illustrates 100 more simulation runs for scenario 4 .

looks at the inner city areas while Scenario 4 includes also city edge areas where idle time is less severe and hence variation is less. Overall, again models that exclude driving time variations in their analysis tend to underestimate fuel consumption and hence $\mathrm{CO}_{2}$ emissions while also it would exclude extreme outcomes where fuel consumption can be extremely high due to high variation as in Scenario 3.

For more representation, Figure 3 depicts 100 more simulation runs. The simulation runs show an acceptable range to represent the variation present in real life scenarios. The results are graphed in a histogram for percent differences of 100 simulation runs.

\section{Results and Conclusion}

The focus of the work looks at the accumulated literature that highlights the topic of green supply chain modeling and/or supply chain management with environmental considerations and the work illustrates the lack of work that investigates material transportation through congested urban areas within the context of supply chain modeling. The work illustrates two cases, one that is predominant in the literature which lumps traveling through congested areas as part of overall transportation and another case that integrates driving time 
variations. The work does not try to argue the case of impact or no impact, of driving time variations, on fuel consumption but rather addresses the approximate estimation of that impact through hundreds of simulation runs.

The results shown in the tables do validate the model as they coincide with the rational that inner city driving would be more taxing on fuel consumption. The edges of the city result in lower $\mathrm{CO}_{2}$ emissions than inner parts of the city due to the prolongation of trip time. The variation becomes higher towards the inner parts of the city due to the higher congestion. The results do not only validate the model but also give us insight into the difference between the factoring of driving time variations and the null. Overall (i.e. in all scenarios), the results illustrate that the difference is higher than $50 \%$ which is significant. The previous tables also illustrate the impact of the driving time variations on the increases in $\mathrm{CO}_{2}$ emissions. This is expected as driving time variations would increase overall fuel consumption however the simulation runs show significantly high percentages of idle time which is an indicator that emission and cost calculations should be adjusted for material transportation through urban areas. Overall, the results solidify the point that urban traffic conditions do adversely affect fuel consumption taking into account that this is an optimal model and the network is optimal.

The work looks at Abu Dhabi's traffic and cannot be generalized to represent world urban areas. Some world cities such Manila, Mexico city, Cairo, Jakarta, and New Delhi can yield higher numbers due to the higher concentration of people and also the poorer road infrastructure. In all, the work demonstrates high percent differences between models that would integrate driving time variations and other that would not.

Someone might argue that material transportation in our world travels thousands of kilometers via sea and hence the travel through urban areas is not very significant in comparison. However, the evolution of more regional trading and more regional partnership is likely to cause the overall transportation cost to be reduced and the transportation time through urban areas (i.e., destination nodes) to become the real bottleneck. In the UAE, more produce is coming from GCC countries and especially from Oman, which is only few hundreds of kilometers away, due to trade agreement between Gulf Cooperation Council (GCC) countries as is the case for the European Union, NAFTA, etc... Historically, produce was shipped (or air freighted) from far away countries such as Philippines, India, Pakistan, Syria, Lebanon, etc... where transportation cost and emission is high and more influential on the overall transportation time and cost so traveling through urban areas becomes negligible when compared to the overall trip. But now with more trading between nations within a given region, the transportation reality in urban areas becomes more pronounced. Take the case of produce that is transported from Oman to the UAE, where the overall transportation time could be less than 3 hours-significant part of the transportation would be through urban areas. The model shows that the possibility of multiple deliveries can be longer than one hour due to urban areas' congestion and hence the travel time through urban areas become more significant with respect to the total transportation time.

This work could serve as a building stone for further research into green supply chain modeling through congested urban areas. Abu Dhabi presents a good case for a congested city with high concentration of resident per kilometer square. More work could be done on other cities with high population concentration. Also further research can be initiated on transportation of specific products to illustrate how significant is transportation cost and emission with respect to production cost and production emission.

\section{References}

1. World Commission on Environment and Development (1987) Our Common Future. Oxford University Press, Oxford, USA.

2. Beamon BM (1998) Supply chain design and analysis: Models and methods. Int J Prod Econ 55: 281-294.

3. Barth M, Boriboonsomsin K (2011) Traffic Congestion and Greenhouse Gases University of California Transportation Center, USA.

4. Amna, Ehtesham, 2004. UAE-GCC Trade Rises 16 Percent. Arab News Newspaper.

5. Seuring S, Muller M (2008) From a literature review to a conceptual framework for sustainable supply chain management. Journal of Cleaner Production 16 1699-1710.

6. Ferretti I, Zanoni S, Zavanella L, Diana A (2007) Greening the aluminum supply chain. Int J Prod Econ 108: 236-245.

7. Nagurney A, Toyasaki F (2003) Supply chain supernetworks and environmental criteria. Transport Res D-TR E 8: 185-213.

8. Bekkering J, Broekhuis TA, van Gernert WJT (2010) Operational modeling of a sustainable gas supply chain. Eng Life Sci 10: 585-594

9. Abdallah T, Diabat A, Simchi-Levi D (2010) A carbon sensitive supply chain network problem with green procurement. 40th International Conference on Computers and Industrial Engineering, Awaji, Japan 1-6.

10. Ramudhin A, Chaabane A, Kharoune M, Paquet M (2008) Carbon market sensitive green supply chain network design. IEEE International Conference on Industrial Engineering and Engineering Management, Singapore 1093-1097.

11. Sundarakani B, De Souza R, Goh M, Wagner SM, Manikandan S (2010) Modeling carbon footprints across the supply chain. Int J Prod Econ 128: 43-50.

12. Gabbar HA (2009) Engineering design of green hybrid energy production and supply chains. Environmental Modeling and Software 24: 423-435.

13. Bojarski AD, Lainez JM, Espuna A, Puigjaner L (2009) Incorporating environmental impacts and regulations in a holistic supply chains modeling: An LCA approach. Comput Chem Eng 33: 1747-1759.

14. Raj KAAD, Rajendran C (2012) A genetic algorithm for solving the fixed charge transportation model: Two-stage problem. Comput Oper Res 39: 2016-2032.

15. Paksoy T, Pehlivan NY, Özceylan E (2012) Application of fuzzy optimization to a supply chain network design: A case study of an edible vegetable oils manufacturer. Appl Math Model 36: 2762-2776.

16. Dondo R, Mendez CA, Cerda J (2011) The multi-echelon vehicle routing problem with cross docking in supply chain management. Comput Chem Eng 35: $3002-3024$

17. Dun-Ji C, Hen-Chin C, Su-Hauan L (2010) The effect of adopting collaborative transportation management by Taiwanese computer manufacturers - Model building and empirical studies. Int J Inform Manage Sci 21: 481-499.

18. Liu K, Zhou Y, Zhang Z (2010) Capacitated location model with online demand pooling in a multi-channel supply chain. Eur J Oper Res 207: 218-231.

19. Ozen L, Daskin M, Coullard C (2009) Facility Location Modeling and Inventory Management with Multisourcing. Transport Sci 43: 455-472.

20. Mahar S, Wright PD (2009) The value of postponing online fulfillment decisions in multi-channel retail/e-tail organizations. Comput Oper Res 36: 3061-3072.

21. Ertogral K (2008) Multi-item single source ordering problem with transportation cost: A Lagrangian decomposition approach. Eur J Oper Res 191: 154-163.

22. Arntzen BC, Brown GG, Harrison TP, Trafton LL (1995) Global Supply Chain Management at Digital Equipment Corporation. Interfaces 25: 69-93.

23. Alzaman C, Bulgak AA, Ramudhin A (2010) Quality in Operational Supply Chain Networks: An Aerospace Case Study. Int J Oper Res 9: 426-442.

24. Fuel Consumption Guide Database (2012) Australian Government, Department of Sustainability, Environment, Water, Population and communities.

25. http://www.tc.gc.ca/eng/programs/environment-fcp-fcguide-629.htm. 